\title{
Competitive effects of herbaceous vegetation on tree seedling emergence, growth and survival: Does gap size matter?
}

\author{
Vandenberghe, Charlotte ${ }^{1,2^{*}}$; Freléchoux, François ${ }^{1,3}$; \\ Gadallah, Fawziah $^{2,4} \&$ Buttler, Alexandre ${ }^{1,2,5}$
}

\begin{abstract}
${ }^{1}$ Swiss Federal Research Institute WSL, Case postale 96, CH-1015 Lausanne, Switzerland; ${ }^{2}$ Laboratory of Ecological Systems ECOS, Swiss Federal Institute of Technology of Lausanne, EPFL, Station 2, CH-1015 Lausanne, Switzerland;

${ }^{3}$ E-mail francois.frelechoux@epfl.ch; ${ }^{4}$ E-mail fawziah.gadallah@gmail.ch; ${ }^{5} E$-mail alexandre.buttler@epfl.ch;

*Corresponding Author; Fax +41 216933913; E-mail charlotte.vandenberghe@epfl.ch
\end{abstract}

\begin{abstract}
Question: What is the effect of gap size on the seedling emergence, growth and survival of four common tree species in wooded pastures?

Location: A pasture in the Jura mountains, Switzerland. Methods: Seeds were sown in a complete three-way factorial design with eight blocks in May 2003. Each block consisted of a competition treatment (four gap sizes including zero) and a mowing treatment (mown and unmown). Emergence, survival and total biomass of tree seedlings of three species (Picea abies, Acer pseudoplatanus and Fagus sylvatica) were measured. A fourth species (Abies alba) failed to germinate.

Results: Gaps had a positive influence on the early stages of tree development for all species. Larger gaps favoured growth and survival more than small gaps. Seedling growth was higher when vegetation around the openings was mown. Mowing the vegetation at gap size zero enhanced both growth and survival compared to unmown vegetation. Mown gaps larger than zero had increased seedling desiccation but decreased seedling predation. Species showed similar trends in their emergence and growth responses to gap size and mowing treatments but for Picea emergence rate was higher and survivorship was lower than for Acer and Fagus.

Conclusions: Gap size does matter for tree seedling success but even in more favourable large gaps only a small percentage of seedlings emerged and survived. The effects of gaps on tree seedling establishment are complex as a result of interactions between biotic and abiotic changes caused by gaps.
\end{abstract}

Keywords: Competition; Opening; Sowing experiment; Trampling; Tree establishment; Wooded pasture.

Nomenclature: Lauber \& Wagner (2000).

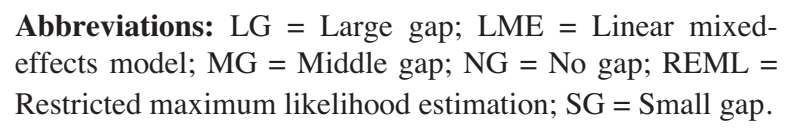

Abbreviations: LG = Large gap; LME = Linear mixedRestricted maximum likelihood estimation; $\mathrm{SG}=$ Small gap.

\section{Introduction}

Gaps are openings in vegetation which allow partial release from competition and provide opportunities for establishment of plants from seed (e.g. Aguilera \& Lauenroth 1995; Bullock et al. 1995; Kotanen 2004) which may be particularly important for woody plants (Mazia et al. 2001; Jurena \& Archer 2003; Rousset \& Lepart 2003). They may be created by local disturbances such as frost heave or plant death but they are most often created by animal activity, such as digging (Goldberg \& Gross 1988; Kotanen 1995) and trampling (Trimble \& Mendel 1995). In wooded pastures, where a mosaic of grasses, shrubs and trees is maintained by grazing (Olff et al. 1999), tree establishment is necessary for the continued existence of the system. Tree seeds will often experience competition from herbaceous vegetation during seedling establishment, so gaps may be essential for the persistence of these systems.

Since plants compete for light, water, nutrients and space, gaps are expected to have positive effects on tree seedling emergence (Nilsson et al. 2002), survival and growth (Prach et al. 1996; Davis et al. 1999; Meiners \& Handel 2000). A reduction in height of the surrounding vegetation, for example by grazing, may also reduce competition and create enhanced conditions for tree seedlings to establish (Karl \& Doescher 1993). However, under dry weather conditions, the moist microclimatic conditions within the sward may be more favourable than exposed soil. Therefore, gaps may also have negative or neutral effects on tree seedling emergence (Burton \& Bazzaz 1991; DeSteven 1991; Gill \& Marks 1991) and survival (Berkowitz et al. 1995).

The physical and biological environments within gaps vary with gap size (Pickett \& White 1985). In cattle-grazed semi-arid grasslands, gaps caused by disturbance are commonly $30-50 \mathrm{~cm}$ across (Hook et al. 1994). Larger gaps have greater light availability and 
are generally drier and warmer due to enhanced evaporation, and seedlings will experience less root competition for soil water and nutrients (Hook et al. 1994). An influence of gap size on emergence, growth and survival in newly created gaps has been found for herbaceous species (McConnaughay \& Bazzaz 1987; Bullock et al. 1995; Kotanen 1997) and for lightdemanding trees in forests (Platt \& Strong 1989). Furthermore, the positive effects of openings, such as increasing light availability may decrease with time due to overgrowth. In contrast, progressive shading of the gaps by surrounding vegetation will cause a reduction in evaporation and provide protection against heat injury, often responsible for high seedling mortality (Farmer 1997). To our knowledge, no information about the influence of gap size in grassy swards on the emergence and subsequent growth and survival of tree seedlings is available.

An understanding of the ability of trees to regenerate in wooded pastures of the Swiss Jura mountains is needed for the preservation of these biodiverse systems in the face of changing agricultural patterns. The ability of different species of tree seedlings to compete with herbs and grasses can be expected to vary due to their variable light requirements, growth strategies (Young \& Young 1992; Brzeziecki \& Kienast 1994) and seed sizes (Seiwa \& Kikuzawa 1996). Therefore, the objective of our study was to investigate the effect of gap size on seedling emergence, growth and survival of each of four tree species. We hypothesized that (1) gaps have a positive effect on seedling emergence, survival and growth due to a reduction in competition; (2) seedling emergence, growth and survival vary among gap sizes due to a different microclimate; (3) the four tree species differ in their ability to emerge, grow and survive in competitive conditions.

\section{Methods}

Study site

A traditionally managed grazed pasture in the Swiss Jura mountains (6 $6^{\circ} 27^{\prime} 26^{\prime \prime}$ E, $46^{\circ} 56^{\prime} 22^{\prime \prime} \mathrm{N}, 1125$ m a.s.1.) was selected. The pasture, dominated by Festuca rubra and Agrostis capillaris, forms part of the fertilized pastures of low and mid altitudes of the Cynosurion. It is surrounded by a Fagus-Abies forest of the AbietiFagenion (Delarze et al. 1998). It has been grazed in spring and summer by cattle for centuries under a rotational grazing system. The growing season of 2003 was particularly hot and dry (Table 1).

We used the four most common local tree species as targets: the evergreen Picea abies and Abies alba and the deciduous Acer pseudoplatanus and Fagus sylvatica. We bought seeds harvested from regional montane sites at altitudes similar to that of our field site from a local nursery (Lobsigen, Switzerland). Seeds were cold-stratified $\left(4{ }^{\circ} \mathrm{C}\right)$ in wet sand to break seed dormancy, for two (Fagus) or eight (Abies and Acer) weeks (Burkart 2000) until one day before sowing. The wings of the Acer seeds were cut off to avoid them being displaced by the wind. Picea seeds were humidified in Petri dishes for 48 h before sowing (Young \& Young 1992). Picea $(n=$ $100)$, Abies $(n=100)$, Acer $(n=50)$ or Fagus seeds $(n=$ 50 ) were sown along a $45-\mathrm{cm}$ sowing line in the centre of each gap in mid-May 2003. Seeds sown on bare soil were slightly covered with soil in order to prevent displacement by wind. Seeds sown into intact vegetation were placed on the soil surface without disturbing the roots of the vegetation. Seed germinability was also tested in May using 240 seeds of each species in a greenhouse pot experiment with a randomized design. Abies seeds did not germinate, either in the field or in the greenhouse, and this species was removed from the analysis and is not discussed further.

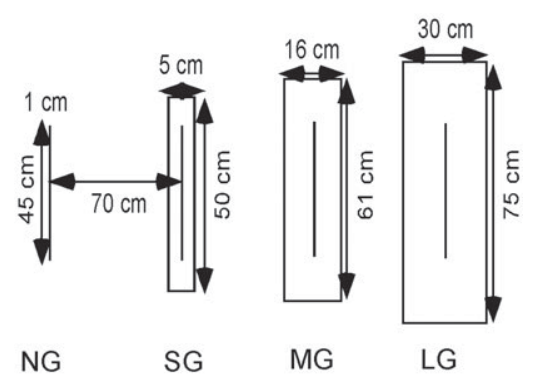

Fig. 1. Experimental design. Subplot measurements. Seeds were sown along a $45 \mathrm{~cm}$ line. Sowing line of SG (small gap), MG (middle gap) and LG (large gap) was 1

cm deep. NG (no gap) represents intact vegetation.
Table 1. Ten-year mean (1994 - 2003) and 2003 annual + monthly (duration of the experiment) mean temperature $\left({ }^{\circ} \mathrm{C} \pm \mathrm{SD}\right)$ and mean precipitation $(\mathrm{mm} \pm \mathrm{SD})$ at the field site (Les Verrières, $\mathrm{CH}$ ).

\begin{tabular}{|c|c|c|c|c|c|c|c|c|c|}
\hline \multirow[b]{3}{*}{ Annual } & \multicolumn{4}{|c|}{10 -year mean } & \multicolumn{5}{|c|}{2003} \\
\hline & \multicolumn{2}{|r|}{${ }^{\circ} \mathrm{C}$} & \multicolumn{2}{|r|}{$\mathrm{mm}$} & \multicolumn{3}{|c|}{${ }^{\circ} \mathrm{C}$} & \multicolumn{2}{|l|}{$\mathrm{mm}$} \\
\hline & 7.4 & \pm 1.0 & 1607.0 & \pm 547.7 & 7.8 & \pm & 1.0 & $980.0 \pm$ & 42.0 \\
\hline May & 9.9 & \pm 2.2 & 190.3 & \pm 69.6 & 10.1 & \pm & 4.1 & $151.2 \pm$ & 9.1 \\
\hline June & 13.0 & \pm 2.2 & 124.5 & \pm 65.9 & 18.0 & \pm & 2.2 & $34.6 \pm$ & 8.5 \\
\hline July & 14.6 & \pm 1.7 & 161.8 & \pm 56.0 & 16.5 & \pm & 3.9 & $146.0 \pm$ & 9.3 \\
\hline August & 15.3 & \pm 2.0 & 146.1 & \pm 45.3 & 20.0 & \pm & 7.9 & $108.2 \pm$ & 7.9 \\
\hline
\end{tabular}




\section{Experimental design}

We used a blocked factorial design with eight blocks and three factors: species, gap size and mowing. Four gap sizes were used: zero (no gap, NG), small (SG), middle (MG) and large (LG) (Fig. 1). To create the gaps, above-ground vegetation was removed and all shoot bases and rhizomes were dug out with a knife. The edges of all gaps, except NG, were trenched to $20 \mathrm{~cm}$ to reduce below-ground competition by neighbouring roots. The mowing treatment had two levels: mown and unmown. The vegetation of NG and around the openings of the mowing treatment was mown bimonthly to a height of $5 \mathrm{~cm}$ and the openings were hand-weeded every two weeks.

Two $38 \mathrm{~m} \times 15 \mathrm{~m}$ exclosures, $100 \mathrm{~m}$ apart, were constructed in the pasture. Within each exclosure, four blocks $(8.5 \mathrm{~m} \times 5.6 \mathrm{~m})$ were placed at 3 - $\mathrm{m}$ intervals. Each block was split into two plots and the mowing treatment was randomly assigned. In each plot, treatments were randomly assigned to each of 16 subplots (i.e. 4 gap treatments $\times 4$ tree species) separated by at least $70 \mathrm{~cm}$ (measured sowing line to sowing line, Fig. 1), resulting in a total of 256 experimental units.

\section{Data collection}

Seven times during the growing season: $04.06,13.06$, $19.06,29.06,18.07,16.08,22.08$, we recorded the number of new seedlings that had appeared and the number of dead or missing seedlings. A seedling was noted as emerged if it had developed cotyledons. Individuals were marked by placing coloured toothpicks next to the seedling, using a different colour for each observation period. The fate of each emerged individual was monitored. The cause of death was noted as: (1) desiccation (seedling intact but dry); (2) predation (observable damage due to insects, slugs or voles or, when seedling was missing, presence of vole faeces or mounds) or (3) missing (seedling not found). Picea seedlings were difficult to detect in the tall vegetation of the unmown NG treatment and were not counted until the final observation, therefore no emergence or survival data are available for these eight subplots. All live seedlings were harvested on 22 August 2003 and separated into leaf, stem and root sections. Each subcomponent was oven-dried and weighed.

Light penetration (\% above-canopy sunlight reaching the soil surface) was measured for each plot in July (for NG the sensor was placed within the herbaceous layer) using a $40 \mathrm{~cm}$ light probe (Decagon Sunfleck Ceptometer, Delta-T Devices LTD, Pullmann, WA, USA).

\section{Data analyses}

All statistical analyses were conducted using $\mathrm{R}$, version 2.0.0 (Anon. 2004). Because there were no significant differences in germination percentage among species in the greenhouse trial (germination percentage \pm SE: Picea $55 \pm 4.1 \%$, Acer $52 \pm 4.0 \%$, Fagus $57 \pm 7.2 \%$; one-way ANOVA, $d f=2, F=1.03$, $p=0.46$ ) no correction was made for germination rates in the field.

\section{Emergence}

A linear mixed-effects model (LME) with restricted maximum likelihood estimation (REML, Pinheiro \& Bates 2000) was fitted to investigate the effect of species and gap size on seedling emergence with block included as a random factor. All seedlings emerged during the first month, when vegetation was short. We therefore excluded the effect of mowing from this analysis. The response variable 'percentage of emerged seedlings' (sum over season) was arcsine transformed to reduce heteroscedasticity. Because the interaction between species and gap size was found to be significant, we analysed each species separately. We have chosen SG as a reference level for significance tests because we were particularly interested in comparing this gap size with others.

\section{Growth}

To investigate the effect of gap size and mowing on total seedling biomass, an LME model was fitted as described above. Seedling biomass (g) was log transformed to reduce heteroscedasticity and LG was chosen as reference level. Comparisons of seedling biomass among species are not meaningful. In addition, an LME model was fitted to measurements of the root:shoot ratio, after log transformation, to estimate the effect of mowing. Total biomass was included in the model as a covariate.

\section{Survival}

The effects of species, gap size and mowing on seedling survival (binary data) were investigated. Again, significant interactions between species, gap size and mowing were found, and we separated the analysis by species. To model a binary response to categorical treatments, we fitted a generalized linear model (GLM) with a binomial distribution and logit link function (Venables \& Ripley 2002). Because block effects are difficult to interpret in a model with categorical data we simplified the model to include 'exclosure' (two levels, see above) as the first explanatory variable. The number of observations for the NG treatment was low, which caused large variances, but a 
re-analysis excluding this gap size produced similar results.

The influence of species and mowing treatment on the cause of death were analysed with a 3-way contingency table. Testing was carried out by using the difference in deviance between the models (GLM with number of dead seedlings as response, three categorical factors, their interactions, Poisson distribution and log link function) with and without the corresponding interaction using 'drop' function in R (Venables \& Ripley 2002). Because the seedlings were not strictly independent experimental units, the results of this analysis should be viewed as indicative rather than definitive.

\section{Results}

\section{Emergence}

A significant interaction between gap size and species was found (Table 2). Emergence rates for Picea were higher for all gap sizes (mean: 24\%) than for Acer (11\%) or Fagus (14\%) (Fig. 2), but the magnitude of the difference varied with gap size. In 11 Acer and ten Fagus subplots no seedlings at all emerged. All species emerged significantly better in openings than in NG. MG and LG did not differ significantly from SG, nor were there consistent trends (Fig. 2).

\section{Growth}

Interactions between gap size and mowing were not significant for any species (Table 3 ). Seedling biomass increased both with gap size and with mowing (Fig. 3). After controlling for total biomass, we found a significant increase in seedling root:shoot ratio in mown plots for Acer $(d f=1 ; F=11.7 ; p<0.0001)$ and Fagus $(d f=$ $1 ; F=23.5 ; p<0.0001)$ but not for Picea $(d f=1 ; \mathrm{F}=1.8$; $p=0.08)$.

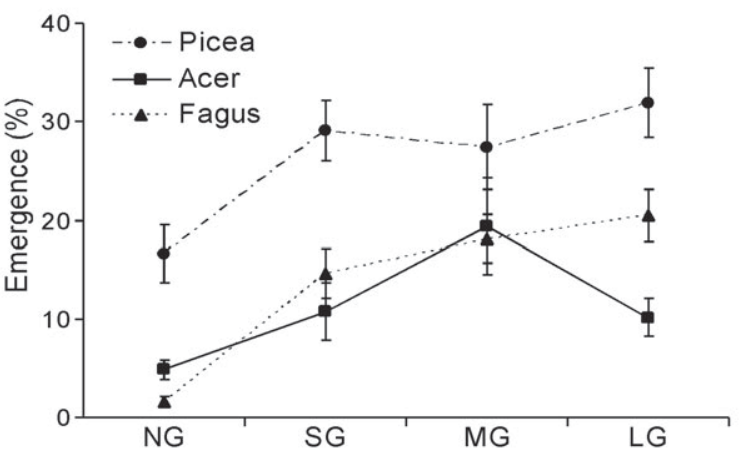

Fig. 2. Effect of species and gap size on seedling emergence $(\%)( \pm 1 \mathrm{SE})$ in both mown and unmown plots. Abbreviations as in Fig. 1.

Survival

A significant interaction between species, gap size and mowing was found ( $d f=5 ; p<0.0001)$, so we report the results for each species separately (Fig. 4).

1. Picea: $27 \%$ of the seedlings survived; the interaction between gap size and mowing was significant $(d f=3 ; p$ $<0.0001)$. Survival was highest in LG and NG and mowing had a positive effect on survival in LG. In SG and MG, mowing had a negative effect.

2. Acer: $64 \%$ of the seedlings survived; significant interaction $(d f=3 ; p=0.01)$ seems to be related to a negative effect of mowing in all openings against a positive effect in NG. Survival was highest in unmown MG and LG.

3. Fagus: $44 \%$ of the seedlings survived; after deleting an outlier (namely the single surviving seedling out of eight in NG unmown), a marginally significant interaction $(d f=3 ; p=0.06)$ was detected. Mowing had no effect in SG, MG or LG, but increased survival in NG, as found for Acer. Survival was highest in MG and LG and under mowing treatment in NG.

The most common cause of seedling death was desiccation (Table 4). Desiccation was higher in mown plots whereas predation was higher in unmown plots (cause $\times$ mowing: $d f=2 ; \chi^{2}=170 ; p<0.0001$ ). Fagus seedlings were relatively more predated and more Acer seedlings were missing (cause $\times$ species: $d f=4 ; \chi^{2}=55$; $p<0.0001)$.

Table 2. Effect of gap size, species and their interaction on seedling emergence and effect of gap size per species on emergence (LME). Mowing treatment is not included in the analysis.

\begin{tabular}{|c|c|c|c|c|c|c|c|c|c|c|c|c|}
\hline & & All & $n=184$ & & Picea & $n=56$ & & Acer & $n=64$ & & Fagus & $n=64$ \\
\hline & df & $F$ & $p$ & df & $F$ & $p$ & df & $F$ & $p$ & df & $F$ & $p$ \\
\hline Gap size & 3 & 23.01 & $<0.0001$ & 3 & 2.466 & 0.0835 & 3 & 4.135 & 0.0105 & 3 & 28.05 & $<.0 .0001$ \\
\hline Species & 2 & 29.45 & $<0.0001$ & & & & & & & & & \\
\hline G.s. $\times$ Spec & 6 & 2.344 & 0.0337 & & & & & & & & & \\
\hline
\end{tabular}


Table 3. Effect of gap size, mowing and their interaction on seedling biomass (LME, analysis per species).

\begin{tabular}{|c|c|c|c|c|c|c|c|c|c|}
\hline & & Picea & $n=113$ & & Acer & $n=209$ & & Fagus & $n=191$ \\
\hline & df & $F$ & $p$ & $\mathrm{df}$ & $F$ & $p$ & $\mathrm{df}$ & $F$ & $p$ \\
\hline Gap size & 3 & 55.29 & $<0.0001$ & 3 & 12.04 & $<0.0001$ & 3 & 10.47 & $<0.0001$ \\
\hline Mowing & 1 & 17.45 & 0.0001 & 1 & 10.96 & 0.0011 & 1 & 5.558 & 0.0195 \\
\hline G.s $\times \mathrm{M}$ & 3 & 2.360 & 0.0762 & 3 & 0.370 & 0.7747 & 3 & 1.157 & 0.3277 \\
\hline
\end{tabular}

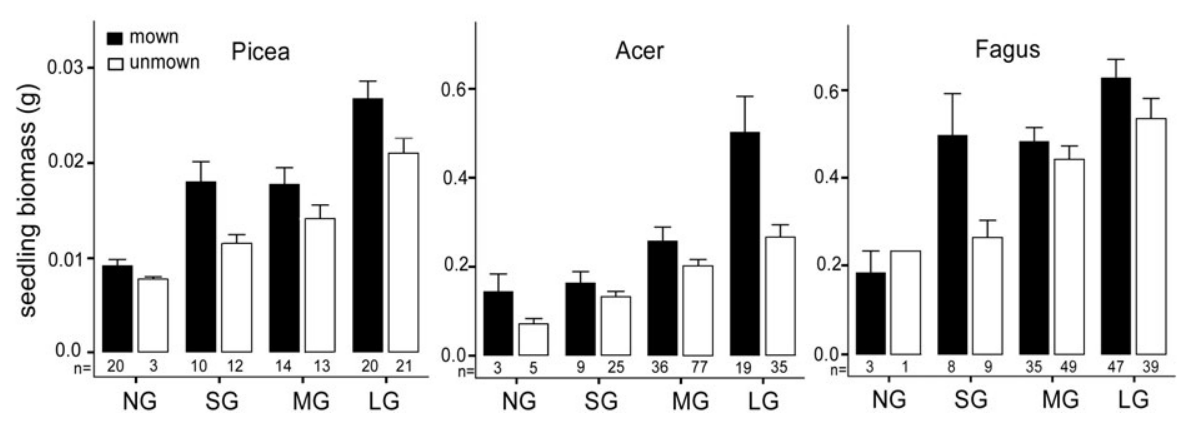

Fig. 3. Effects of gap size and mowing on total seedling biomass ( $\pm 1 \mathrm{SE}$ ). Abbreviations as in Fig. 1. Note change of scale for Picea.

\section{Discussion}

\section{Seedling emergence}

As hypothesized, seedling emergence increased in openings for all species, a result consistent with studies where seedbed scarification and vegetation removal improves tree seedling emergence (e.g. Brang 1998; Nilsson et al. 2002; Agestam et al. 2003). Even under the dry conditions of 2003, we did not detect facilitation by herbaceous species, which could be expected due to a more moist micro-environment and protection from predators, as has been observed in some old-fields (e.g. DeSteven 1991; Burton \& Bazzaz 1991). Acer and Fagus had very low emergence rates in intact vegetation, probably because the radicle of seedlings desiccated before penetrating the soil (pers. obs. C.V.). This is a common cause of failure for tree seedlings trying to
Table 4. Percentage of seedlings that died due to desiccation, predation or missing.

\begin{tabular}{llccc}
\hline \multirow{2}{*}{ Picea } & & Desiccation & Predation & Missing \\
\multirow{4}{*}{ Acer } & Mown & 55.5 & 3.4 & 0.4 \\
& Unmown & 28.9 & 9.9 & 1.9 \\
\multirow{3}{*}{ Fagus } & Mown & 43.6 & 1.6 & 0.8 \\
& Unmown & 28.2 & 12.9 & 12.9 \\
& Mown & 43.7 & 7.4 & 0.0 \\
& Unmown & 27.3 & 20.4 & 1.2 \\
\hline
\end{tabular}

penetrate the litter layer in forests (Farmer 1997; Caccia \& Ballaré 1998). Picea emergence may have been more successful because the small seeds could more easily fall into crevices or be buried by shifting soil, and thus obtain greater protection from seed predation and better soil contact for water imbibition. Furthermore, fewer Picea seeds may have been eaten by mice than Fagus and Acer seeds due to their lower energy content

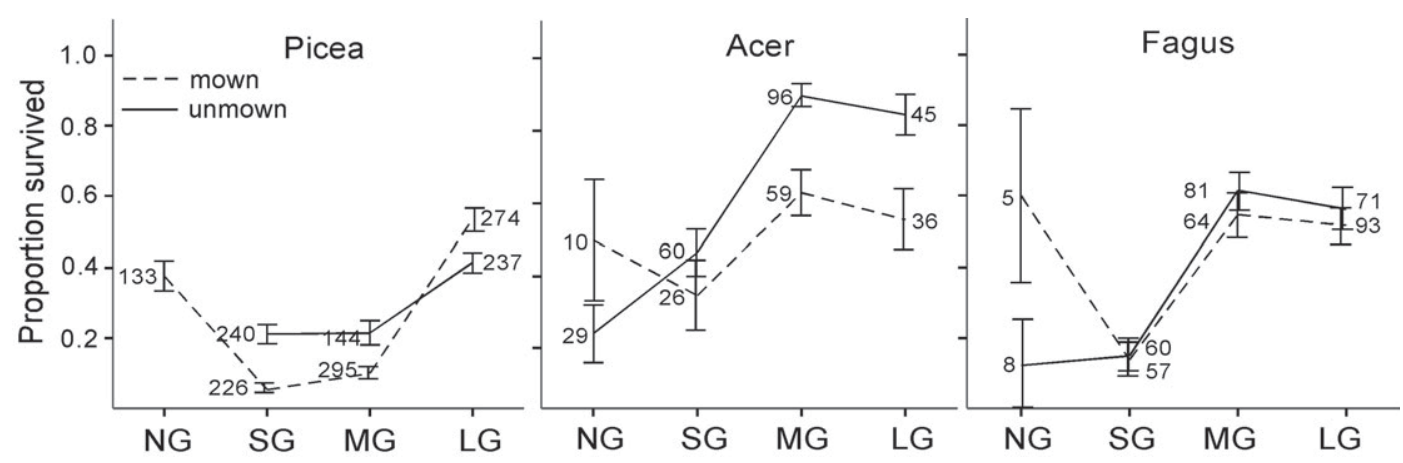

Fig. 4. Effect of gap size and mowing on proportion $( \pm 1 \mathrm{SE})$ of surviving seedlings $=$ no. seedlings survived $/$ no.seedlings emerged for each species. Next to each error bar number of observed seedlings is given. Abbreviations as in Fig. 1. 
(Jennings 1976). Under natural conditions, Acer and Fagus seeds will fall during autumn and the heavy snow will help them penetrate the litter layer, enhancing the penetration of the root into the soil and thus emergence in spring.

No significant differences were found between the three sizes of openings for any of the species. Field observations suggested that the openings were considerably drier than surrounding soil, probably due to air flow in trenches between the plot and the surrounding soil, resulting from the method used to create the openings (pers. obs. C.V.). Unusually warm and dry conditions during the growing season of 2003 may have dried the soil of all gaps enough to mask potential differences in emergence between sizes of openings, and our results may be more indicative of patterns to be expected under climate change than past patterns.

\section{Seedling growth}

Vegetation removal had a strong positive effect on seedling growth, as has been found by others (Berkowitz et al. 1995; Burton \& Bazzaz 1995; Nilsson \& Örlander 1999). Reduced water, nitrogen and light availability in the herbaceous vegetation often reduces tree seedling growth as found by studies using transplants (Kübner et al. 2000; Thevathasan et al. 2000; Löf et al. 2004).

For all species, seedling biomass increased with increasing gap size and with mowing of the surrounding vegetation, probably due, at least in part, to increasing light availability. Over time, the unmown openings in the sward became revegetated and shaded. The amount of light reaching the soil was reduced more rapidly in the small gaps, because vegetation around the gaps more quickly overgrew the small gaps than the larger ones. In mown plots, light availability in openings of different size was similar (Fig. 5), so other factors must have played a role to produce the gap size effect in these plots. There was minimal competition for water and nutrients with root systems of surrounded vegetation since the gaps were trenched. We suggest that the small gaps, which had a smaller soil volume and a large evaporative surface due to a poor connection with surrounding soil (a result of soil shrinkage under the unusual weather conditions), dried out more rapidly than the larger gaps, causing reduced seedling biomass. Intraspecific competition may also have reduced seedling growth more in the small and middle gaps than in the large gaps, as has been found for Picea (Li \& Wilson 1998).

The higher root:shoot ratio in mown plots of Acer and Fagus may reflect a decreased stem allocation due to decreasing light competition, and/or increasing root allocation due to water limitation in the mown plots. Madsen (1994) found that at low levels of soil water content, both growth and root:shoot ratio of Fagus seedlings increased with increased light. Water and nutrient stress tend to increase allocation of biomass to the roots and increase length of the taproot (Nambiar \& Sands 1993; Meiners \& Handel 2000). Our study may have been too short to observe effects on the allocation pattern of the small Picea seedlings, although the root:shoot ratio of one-year old Pinus saplings were found to be relatively stable even under severe water deficits (Watt et al. 2003).

\section{Seedling survival}

In general, survival tended to increase with gap size. Variations among species may be caused in part by a relatively larger importance of surface humidity for Picea seedling survival, since these seedlings are smaller and more shallow-rooted than the two deciduous species. This greater sensitivity may explain the overall higher mortality rate for Picea in the dry conditions of 2003.

Relative survivorship was higher in the intact vegetation than we expected. We suspect that established seedlings in the intact vegetation were less exposed to direct solar radiation and better protected from heat and drought than in openings. Berkowitz et al. (1995) proposed similar mechanisms for the facilitation of survival of maple seedlings. In addition, a reduced transpiration surface of the sward, due to grazing or mowing, may have led to increased soil water availability (cf. Karl \& Doescher 1993).

For all species, seedlings in large gaps had a higher survival rate than in small gaps. As we suggested for the effects on growth, desiccation risk and intraspecific

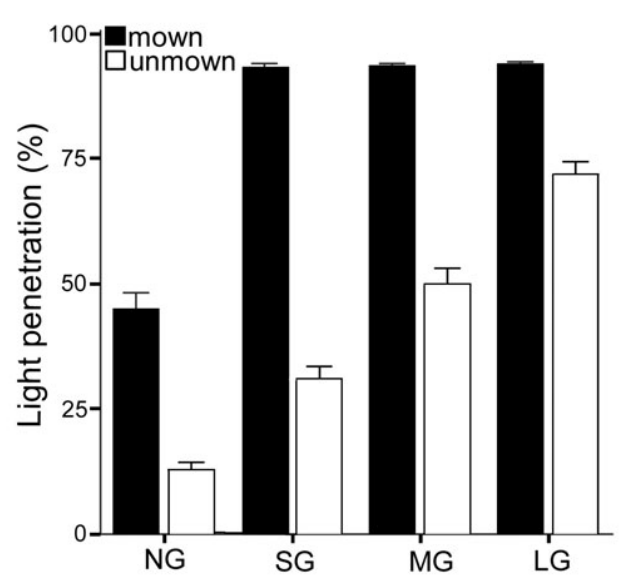

Fig. 5. Light penetration ( $\%, \pm 1 \mathrm{SE})$ to the soil for each gap and mowing treatment. Results of two-way ANOVA (response variable was arcsine transformed) for interaction gap size $\times$ mowing: $d f=3, F=26.6, p<0.0001$. Abbreviations as in Fig. 1. 
competition may have been higher in small gaps. Increased dryness and higher soil surface temperature in the mown plots probably also caused higher seedling mortality than in unmown plots. The lack of a mowing effect for Fagus may have been because higher predation rates in the unmown plots balanced the increased desiccation rates in mown plots. The main predators at our study were rodents, but slugs and insects also predated some seedlings (cf. Agestam et al. 2003). Seedling predation for all species was higher in unmown plots, probably because these plots provided a safer and more attractive environment for rodents and slugs. Gill \& Marks (1991) and Ostfeld \& Canham (1993) demonstrated that intact vegetation can have an indirect effect on seedling survival by providing a protective habitat for small mammal herbivores that are voracious consumers of newly emerged tree seedlings.

\section{Conclusions and ecological implications}

The influence of gaps on tree-grass dynamics are of concern in many grazed ecosystems such as wooded pastures and savannas (Archer 1995; Scanlan 2002). We found that gaps have a positive influence on early stages of tree development. In addition, size and mowing related differences in the characteristics of the physical (light, moisture and temperature) and biological (herbaceous vegetation, predators) environment of gaps interacted to influence tree seedling emergence, growth and survival. Although we found larger gaps to favour tree seedling growth and survival, fewer than $20 \%$ of the seeds emerged and survived for three months in favourable large gaps. The dry weather conditions of 2003 were probably not favourable for early tree establishment and this leads us to speculate that increased frequency of such conditions under climate change may need to be taken into account when managing tree pastures.

Compared to our artificial gaps, emerged seedlings in natural gaps will have greater competition for belowground resources because natural gaps are not trenched. Competition for soil water and other below-ground resources is then higher in smaller gaps, improving the probability of establishment in large gaps. Further study is needed to understand the balance of above- and below-ground effects under different weather conditions. The duration of moist conditions at the surface may be a critical constraint for tree seedling establishment. Since the characteristics of an opening will depend on the method of its formation and weather conditions, different results in tree emergence and establishment may be expected in different years (Nilsson et al. 2002).
Acknowledgements. We thank the agronomic research stations Agroscope Changins (RAC) for access to La Petite Ronde and for providing material. We acknowledge the support of the National Centre of Competence in Research (NCCR). This study was financially supported by MAVA and the Swiss Federal Research Institute WSL (programme Walddynamik); it forms part of the $\mathrm{PhD}$ thesis of C.V.

\section{References}

Anon. 2004. R: A language and environment for statistical computing. R Foundation for Statistical Computing, Version 2.0.0, Vienna, AT. http: //www.R-project.org/

Agestam, E., Eko, P.M., Nilsson, U. \& Welander, N.T. 2003. The effects of shelterwood density and site preparation on natural regeneration of Fagus sylvatica in southern Sweden. Forest Ecol. Manage. 176: 1-73.

Aguilera, M.O. \& Lauenroth, W.K. 1995. Influence of gap disturbances and types of microsites on seedling establishment in Bouteloua gracilis. J. Ecol. 83: 87-97.

Archer, S. 1995. Harry Stobbs Memorial Lecture, 1993. Herbivore mediation of grass-woody plant interactions. Trop. Grasslands 29: 18-235.

Berkowitz, A.R., Canham, C.D. \& Kelly, V.R. 1995. Competition vs facilitation of tree seedling growth and survival in early successional communities. Ecology 76: 1156-1168.

Brang, P. 1998. Early seedling establishment of Picea abies in small forest gaps in the Swiss Alps. Can. J. For. Res. 28: 626-639.

Brzeziecki, B. \& Kienast, F. 1994. Classifying the life-history strategies of trees on the basis of the Grimian model. Forest Ecol. Manage. 69: 167-187.

Bullock, J.M., Hill, B.C., Silvertown, J. \& Sutton, M. 1995. Gap colonization as a source of grassland community change - effects of gap size and grazing on the rate and mode of colonization by different species. Oikos 72: 273282.

Burkart, A. 2000. Kulturblätter. Angaben zur Samenernte, Klengung, Samenlagerung, Samenausbeute und zur Anzucht von Baum-und Straucharten. Eidg. Forschungsanstalt WSL, Birmensdorf, CH.

Burton, P.J. \& Bazzaz, F.A. 1991. Tree seedling emergence on interactive temperature and moisture gradients and in patches of old-field vegetation. Am. J. Bot. 78: 131-149.

Burton, P.J. \& Bazzaz, F.A. 1995. Ecophysiological responses to tree seedlings invading different patches of old-field vegetation. J. Ecol. 83: 99-112.

Caccia, F.D. \& Ballaré, C.L. 1998. Effects of tree cover, understory vegetation and litter on regeneration of Douglas-Fir (Pseudotsuga menziesii) in southwestern Argentina. Can. J. For. Res. 28: 683-692.

Davis, M.A., Wrage, K.J., Reich, P.B., Tjoelker, M.G., Schaeffer, T.\& Muermann, C. 1999. Survival, growth and photosynthesis of tree seedlings competing with herbaceous vegetation along a water-light-nitrogen gradient. Plant Ecol. 145: 341-350.

Delarze, R., Gonseth, Y. \& Gallandat, P. 1998. Guide des milieux naturels de Suisse. OFEFP, Pro Natura, Delachaux \& Niestlé, Lausanne, $\mathrm{CH}$. 
DeSteven, D. 1991. Experiments on mechanisms on tree establishment in old-field succession: seedling emergence. Ecology 72: 1066-1075.

Farmer, Jr. R.E. 1997. Seed ecophysiology of temperate and boreal zone forest trees. St. Lucie Press, Delray Beach, FL, US

Gill, D.S. \& Marks, P.L. 1991. Tree and shrub seedling colonization of old fields in central New-York. Ecol. Monogr. 61: 83-205.

Goldberg, D.E. \& Gross, K.L. 1988. Disturbance regimes of midsuccessional old fields. Ecology 69: 1677-1688.

Hook, P.B., Lauenroth, W.K. \& Burke, I.C. 1994. Spatial patterns of roots in a semiarid grassland-abundance of canopy openings and regeneration gaps. J. Ecol. 82: 485494.

Jennings, T.J. 1976. Seed detection by wood mouse Apodemus sylvaticus. Oikos 27: 174-177.

Jurena, P.N. \& Archer, S. 2003. Woody plant establishment and spatial heterogeneity in grasslands. Ecology 84: 907919.

Karl, M.G. \& Doescher, P.S. 1993. Regulating competition on conifer plantations with prescribed cattle grazing. For. Sci. 39: 405-418.

Kotanen, P.M. 1997. Effects of gap area and shape on recolonization by grassland plants with differing reproductive strategies. Can. J. Bot. 75: 352-361.

Kotanen, P.M. 1995. Responses of vegetation to a changing regime of disturbance-effects of feral pigs in a Californian coastal prairie. Ecography 18: 190-199.

Kotanen, P.M. 2004. Revegetation following soil disturbance and invasion in a Californian meadow: a 10-year history of recovery. Biol. Invasions 6: 245-254.

Kübner, R., Reynolds, P.E. \& Bell, F.W. 2000. Growth response of Picea mariana seedlings to competition for radiation. Scand. J. For. Res. 15: 334-342.

Lauber, K. \& Wagner, G. 2000. Flora Helvetica, flore illustrée de Suisse. Haupt, Berne, $\mathrm{CH}$.

Li, X.D. \& Wilson, S.D. 1998. Facilitation among woody plants establishing in an old field. Ecology 79: 2694-2705.

Löf, M., Thomsen, A. \& Madsen, P. 2004. Sowing and transplanting of broadleaves (Fagus sylvatica L., Quercus robur L., Prunus avium L. and Crataegus monogyna Jacq.) for afforestation of farmland. For. Ecol. Manage. 188: 113123.

Madsen, P. 1994. Growth and survival of Fagus sylvatica seedlings in relation to light-intensity and soil-water content. Scand. J. For. Res. 9: 316-322.

Mazia, C.N., Chaneton, E.J., Ghersa, C.M. \& Leon, R.J.C. 2001. Limits to tree species invasion in pampean grassland and forest plant communities. Oecologia 128: 594602.

McConnaughay, K.D.M. \& Bazzaz, F.A. 1987. The relationship between gap size and performance of several colonizing annuals. Ecology 68: 411-416.

Meiners, S.J. \& Handel, S.N. 2000. Additive and nonadditive effects of herbivory and competition on tree seedling mortality, growth and allocation. Am. J. Bot. 87: 18211826.

Nambiar, E.K.S. \& Sands, R. 1993. Competition for water and nutrients in forests. Can. J. For. Res. 23: 1955-1968.

Nilsson, U. \&. Örlander, G. 1999. Water uptake by planted Picea abies in relation to competing field vegetation and seedling rooting depth on two grass-dominated sites in Southern Sweden. Scand. J. For. Res. 14: 312-319.

Nilsson, U., Gemmel, P., Johansson, U., Karlsson, M. \& Welander, T.2002. Natural regeneration of Norway spruce, Scots pine and Birch under Norway spruce shelterwoods of varying densities on a mesic-dry site in southern Sweden. For. Ecol. Manage. 161: 133-145.

Olff, H., Vera, F.W.M., Bokdam, J., Bakker, E.S., Gleichman, J.M., De Maeyer, K. \& Smit, R. 1999. Shifting mosaics in grazed woodlands driven by the alternation of plant facilitation and competition. Plant Biol. 1: 127-137.

Ostfeld, R.S. \&. Canham, C.D. 1993. Effects of meadow vole population density on tree seedling survival in old fields. Ecology 74: 1792-1801.

Pickett, S.T.A. \& White. P.S. 1985. The ecology of natural disturbance and patch dynamics. Academic Press, Orlando, FL, US

Pinheiro, J.C. \& Bates, D.M. 2000. Mixed-effects models in S and S-plus. Springer, New York, NY, US.

Platt, W.J. \& Strong, D.R. 1989. Special feature-treefall gaps and forest dynamics-gaps in forest ecology. Ecology 70: 535-576.

Prach, K., Leps, J. \& Michalek, J. 1996. Establishment of Picea abies seedlings in a central European mountain grassland: an experimental study. J. Veg. Sci. 7: 681-684.

Rousset, O. \& Lepart, J. 2003. Neighbourhood effects on the risk of an unpalatable plant being grazed. Plant Ecol. 165: 197-206.

Scanlan, J.C. 2002. Some aspects of tree-grass dynamics in Queensland's grazing lands. Rangeland J. 24: 56-82.

Seiwa, K. \& Kikuzawa, K. 1996. Importance of seed size for the establishment of seedlings of five deciduous broadleaved tree species. Vegetatio 123: 51-64.

Thevathasan, N.V., Reynolds, P.E., Kuessner, R. \& Bell, W.F. 2000. Effects of controlled weed densities and soil types on soil nitrate accumulation, spruce growth, and weed growth. For. Ecol. Manage. 133: 135-144.

Trimble, S.W. \& Mendel, A.C. 1995. The cow as a geomorphic agent-a critical review. Geomorphology 13: 233-253.

Venables, W.N \& Ripley, B.D. 2002. Modern applied statistics with $S$. 4th ed. Springer, New York, NY, US.

Watt, M.S., Whitehead, D., Mason, E.G., Richardson, B. \& Kimberley, M.O. 2003. The influence of weed competition for light and water on growth and dry matter partitioning of young Pinus radiata, at a dryland site. For. Ecol. Manage. 183: 363-376.

Young, J.A. \& Young, C.G. 1992. Seeds of woody plants in North America. Dioscorides Press, Portland, OR, US.

Received 6 December 2005; Accepted 25 April 2006 Co-ordinating Editor: B. Peco. 